\title{
International Evidence on the Equity Premium Puzzle and Time Discounting
}

\author{
Marc Oliver Rieger* \\ University of Trier, Germany \\ Mei Wang ${ }^{\dagger}$ \\ WHU Otto Beisheim School of Economics, Germany \\ Thorsten Hens ${ }^{\ddagger}$ \\ University of Zurich, Switzerland \\ NHH Bergen, Norway
}

We examine time discounting factors in an international survey. Our analysis reveals a significant relationship between time discount factors and historical equity premiums across 27 countries. This result implies that higher historical equity risk premiums are observed in countries where survey participants tend to be more short-term oriented. This finding is consistent with the explanation of the equity premium puzzle provided by myopic loss aversion. (JEL: G02, G11, D81)

Keywords: equity risk premium, time discounting, myopic loss aversion, cultural finance

\section{The Equity Premium Puzzle - An Overview}

Stocks are riskier than bonds. Therefore, it is only natural for stocks to have a higher expected return than bonds in a market dominated by risk-averse investors. When estimating how large this difference should be, Mehra \& Prescott (1985) noticed that the discrepancy is too large to be easily explained by risk aversion. This finding is known as the equity

\footnotetext{
* University of Trier, Department IV, 54286 Trier, Germany, mrieger@uni-trier.de. † WHU Otto Beisheim school of Economics, Vallendar, Germany, mei.wang@whu.edu.

‡ Swiss Finance Institute professor at the IBF, University of Zurich, Switzerland and NHH Bergen, Norway, thorsten.hens@bf.uzh.ch.
}

(Multinational Finance Journal, 2013, vol. 17, no. 3/4, pp. 149-163)

(C) Multinational Finance Society, a nonprofit corporation. All rights reserved. DOI: $10.17578 / 17-3 / 4-2$ 
premium puzzle.

In the past, many explanations have been suggested for this puzzle (see Mehra (2008) for an overview). Possible explanations involved consumption- based generalized expected utility models, as suggested by Epstein \& Zin (1991), Constantinides (1990), Abel (1990) and Campbell (1999), taking into account additional risk provided by rare and disastrous events (Rietz 1988, Mehra \& Prescott 1988, Barro 2006) or idiosyncratic income shocks (Constantinides \& Duffie 1996, Krebs 2000), liquidity limitations (Bansal \& Coleman 1996, Holmström 1998), borrowing constraints (Constantinides, Donaldson \& Mehra 2002) and tax reasons (McGrattan \& Prescott 2003, McGrattan \& Prescott 2005). It has also been found that an industry group's higher risk leads to higher equity risk premiums (Athanassakos 1998).

Behavioral factors have also been suggested, most notably aversions to ambiguity (Chen \& Epstein 2002, Barillas, Hansen \& Sargent 2009, Gollier 2011, Rieger \& Wang 2012) and myopic loss (Benartzi \& Thaler 1995, Barberis \& Huang 2008). Thus far, the general conclusion of this line of research is that various factors might contribute to explaining the equity premium puzzle but that none of these factors alone can provide a complete explanation.

Although most of the explanations mentioned above have a solid theoretical background, it is rather difficult to provide empirical evidence for them. Our approach in this article is to compare equity premiums in a number of different countries to investigate systematic differences. Our article is structured as follows. In the next section, we provide a more detailed description of the behavioral model based on myopic loss aversion going back to Benartzi \& Thaler (1995) and Barberis \& Huang (2008) with a particular focus on how hyperbolic discounting is related to equity premiums based on these models. In section III, we present empirical results on time discounting and the equity premiums from a variety of countries around the world, showing that the present bias is indeed a significant and robust predictor of equity premiums. Moreover, we show that cultural factors (particularly uncertainty avoidance as defined by Hofstede (2001)) drive differences in hyperbolic discounting and thus indirectly influence the size of equity premiums. Section IV concludes the paper.

\section{Myopia and the Equity Premium}

The key idea through which the concept of myopic loss aversion 
explains the size of the equity premium can be summarized as follows: Investors are, on average, loss averse, i.e., their utility decreases sharply if they fall behind a reference point, which is typically their initial wealth level. In other words, investments that allow for losses appear less attractive to investors. When investing in stocks over a long period, the probability of losses decreases due to overall increases in stock prices in the long run. In contrast, myopic investors prefer to concentrate on the potential returns of their assets within a relatively short time frame. Accordingly, such investors would be less inclined to invest in stocks because their probability of short-run losses is relatively high. For such investors, bonds are much more attractive because their probability of generating a loss is much smaller in the short run.

The above explanation has been suggested by Benartzi \& Thaler (1995) and Barberis \& Huang (2008). The calibration of this model with reasonable utility functions as provided by Prospect Theory yields a relatively good fit to the size of the equity premium when assuming an average time horizon of approximately one year (Benartzi \& Thaler 1995, Zeisberger, Langer \& Trede 2007). Thaler, Tversky, Kahneman \& Schwartz (1997) and Gneezy \& Potters (1997) independently conducted the first experimental studies to test the effects of myopia and loss aversion on investment decisions. In a market experiment, Gneezy, Kapteyn \& Potters (2003) further confirmed that myopia led to lower prices for risky assets. Although these studies certainly offer convincing evidence, it seems difficult to find direct empirical proof for this theory using real market data because variations in relevant parameters, such as the time preferences of individual investors, are typically not observable. Moreover, the extent to which myopia can lead to an equity premium at the aggregate level within one country is not clear.

Our method differs from the approaches mentioned above in that we consider a number of different stock markets. We focus on the impacts of myopia, which is measured by a time discounting parameter from our international survey. We would expect the equity premium to be higher in countries where investors have behavioral preferences that are more likely to lead to myopic loss aversion. ${ }^{1}$ In our study, we will mostly concentrate on time discounting because steeper time discounting will

1. This might not necessarily be true at first glance because foreign investors can also invest in a particular country. In reality, however, the well-documented home bias prevents a majority of investors from investing outside their own countries. Therefore, the performance of a stock market in a certain country is still mostly determined by the investors from that country. 
obviously lead to a shorter investment horizon.

In the following section, we will describe how we obtained time discounting and equity risk premium data across countries and how they were found to be correlated.

\section{Empirical Results On Time Discounting and the Equity Premium}

\section{A. Methodology}

To measure time discounting across countries, we used data from an international study on risk and time preferences (INTRA) as reported in Wang, Rieger \& Hens (2011). In this survey, time discounting parameters were measured based on hypothetical choices between earning a fixed reward now or earning a larger reward in one or ten years. The two examined questions were as follows:

Please consider the following alternatives

A. a payment of $\$ 100$ now

B. a payment of $\$ X$ one year from now

$X$ has to be at least $\$ \ldots$, such that B is as attractive as A.

Please consider the following alternatives

A. a payment of $\$ 100$ now

B. a payment of $\$ X 10$ years from now

$X$ has to be at least $\$$ such that B is as attractive as A.

Based on the responses to these survey questions, we estimated the hyperbolic discount factors and obtained the median value for each country. The Quasi-hyperbolic Discounting model is usually defined in discrete time periods as follows:

$$
u\left(x_{0}, x_{1}, \ldots, x_{T}\right)=u\left(x_{0}\right)+\sum_{t=1}^{T} \beta \delta^{t} u\left(x_{t}\right)
$$

where $t$ is the length of time, $\delta$ is the long-term discount factor and $\beta$ is the hyperbolic discount factor that discounts the immediate future against the present. The values for $\beta$ consequently vary on the interval 
$(0,1]$, where $\beta=1$ is true when only classical exponential time discounting occurs rather than hyperbolic time discounting. The parameters $\delta$ and $\beta$ can be inferred from the responses $F_{\text {1year }}$ and $F_{10 \text { year }}$ :

$$
\begin{gathered}
\delta=\left(\frac{F_{1 \text { year }}}{F_{10 \text { year }}}\right)^{1 / 9} \\
\beta=\frac{100}{\delta F_{1 \text { year }}}
\end{gathered}
$$

To measure the equity risk premium, we performed an extensive survey of the existing studies that estimate historical equity risk premiums in certain countries. The studies that were included in our analysis provided numbers for a total of 39 countries, where several countries had a larger number of different measurements (e.g., there were 14 studies on the U.S. and 10 studies each on France, Germany and UK). There are several ways to measure the equity premium. Most notably, it can be measured as the premium on stocks compared to that on long-term bonds or T-bills. In order to include as many countries as possible, we decided to use long-term bonds as a benchmark whenever available and T-bills otherwise. Of the studies that we found in the literature (Alpalhao \& Alves 2005, Barro 2006, Campbell 2003, Dimson, Marsh \& Staunton 2006, Goetzmann \& Ibbotson 2006, Kyriacou, Madsen \& Mase 2004, Lally \& Marsden 2004, Madsen 2004, Mehra 2003, Mehra 2007, Mehra 2008, Mehra \& Prescott 1985, Mehra \& Prescott 2003, Canova \& Nicolo 2003, San Martin \& Lillo 2003, Schackman 2006, Salomons \& Grootveld 2003), a few had to be omitted because they had subsequently been updated by new versions from the same authors. The remaining studies have been equally weighted to determine the average equity premium across studies. ${ }^{2}$ As a robustness check, we repeated the analysis using only the "best" equity risk premium, i.e., the one that was calculated with the longest period of data. The results were, however, very similar, which is not surprising given that both measures have a correlation of $\rho=0.972(p<0.001)$.

It should be mentioned that there are obviously some limitations to

2. This method of estimating the equity premium for a number of countries has also been used in Rieger \& Wang (2012). 
TABLE 1. Equity Premium, discount factor and one-year discount rate by country

\begin{tabular}{|c|c|c|c|}
\hline Country & $\operatorname{ERP}(\%)$ & $\begin{array}{c}\text { Hyperbolic } \\
\text { discount factor }(\beta)\end{array}$ & $\begin{array}{l}\text { One-year implicit } \\
\text { interest rate }\end{array}$ \\
\hline Argentina & 19.03 & 0.60 & 1.00 \\
\hline Australia & 5.75 & 0.97 & 0.14 \\
\hline Austria & 5.69 & 0.70 & 0.60 \\
\hline Belgium & 7.59 & 0.75 & 0.50 \\
\hline Canada & 5.32 & 0.65 & 0.50 \\
\hline Chile & 26.17 & 0.24 & 4.00 \\
\hline China & 8.04 & 0.51 & 2.00 \\
\hline Colombia & 10.62 & 0.61 & 0.79 \\
\hline Czech Rep & 5.52 & 0.69 & 0.67 \\
\hline Denmark & 6.84 & 0.82 & 0.50 \\
\hline Finland & 18.73 & 0.86 & 0.25 \\
\hline Germany & 5.49 & 0.60 & 1.00 \\
\hline Greece & 15.89 & 0.38 & 2.50 \\
\hline Hong Kong & 20.95 & 0.65 & 1.00 \\
\hline Hungary & 24.00 & 0.69 & 0.71 \\
\hline India & 10.38 & 0.60 & 1.00 \\
\hline Ireland & 5.95 & 0.76 & 0.50 \\
\hline Israel & 8.80 & 0.65 & 1.00 \\
\hline Italy & 7.86 & 0.64 & 1.00 \\
\hline Japan & 8.58 & 0.70 & 1.00 \\
\hline Malaysia & 10.23 & 0.26 & 4.00 \\
\hline Mexico & 17.84 & 0.55 & 1.20 \\
\hline Netherlands & 6.09 & 0.89 & 0.28 \\
\hline New Zealand & 5.51 & 0.76 & 0.50 \\
\hline Norway & 8.04 & 0.73 & 0.67 \\
\hline Portugal & 14.20 & 0.60 & 1.00 \\
\hline Russia & 24.00 & 0.20 & 5.67 \\
\hline South Korea & 10.02 & 0.76 & 0.82 \\
\hline Spain & 4.84 & 0.74 & 0.50 \\
\hline Sweden & 9.63 & 0.85 & 0.33 \\
\hline Switzerland & 6.84 & 0.60 & 1.00 \\
\hline Taiwan & 14.22 & 0.70 & 1.00 \\
\hline Thailand & 11.78 & 0.98 & 0.20 \\
\hline Turkey & 25.80 & 0.65 & 1.00 \\
\hline UK & 5.12 & 0.63 & 1.00 \\
\hline USA & 6.11 & 0.78 & 0.50 \\
\hline
\end{tabular}

this approach; in particular, the time frame on which the equity premium has been computed varies widely among the different studies due to data availability. Studies on the U.S. or UK in particular typically 


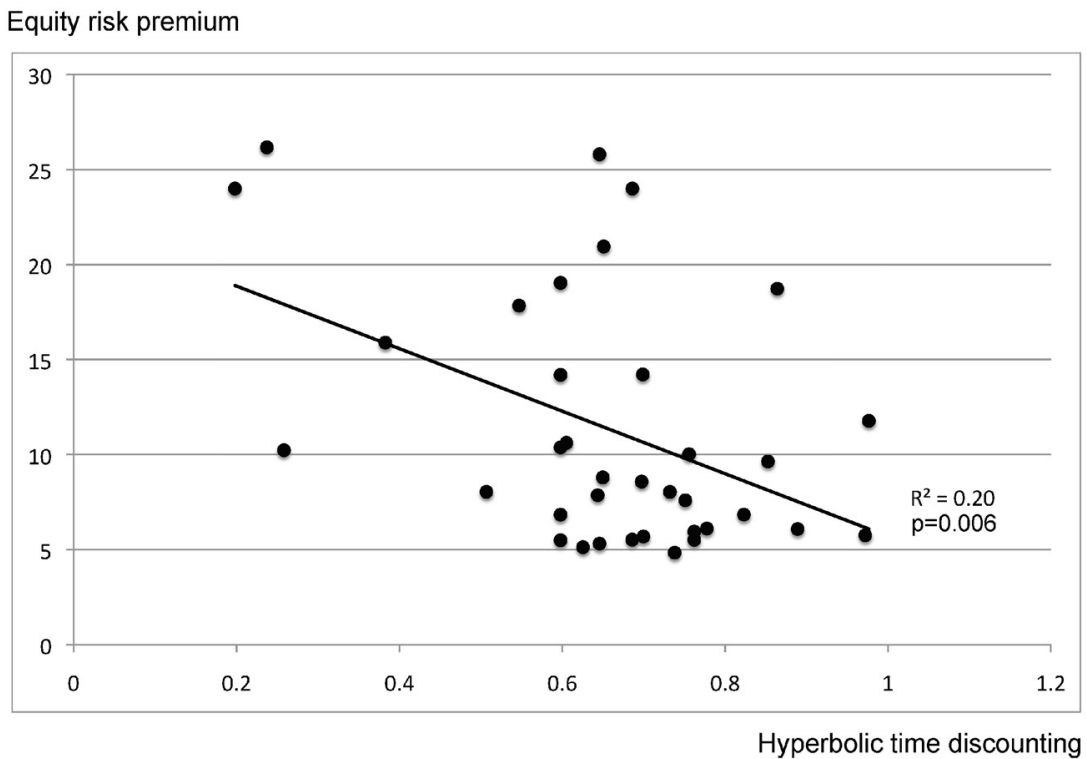

FIGURE 1.-Correlation between present time bias and equity risk premium

involve long-term data (often more than 100 years), whereas those on emerging markets usually involve only approximately 20 years of data or less. Improving on this approach will only be possible in the future when longer time series become available for emerging markets.

\section{B. Results}

Table 1 presents average historical equity risk premiums together with the hyperbolic discount factor $\beta$ and one-year discount rate at the country level. A first look at the relation between the present time bias and the equity premium in 36 countries (the countries in which both measurements are available) is shown in figure 1 . The long-term discount factor $\delta$ is rather homogenous across countries, whereas the hyperbolic discount factor $\beta$ turns out to be a significant predictor of equity risk premiums. There is a highly significant negative correlation $(\rho=-0.50)$ between the two variables: In countries where $\beta$ is smaller (larger time discounting and stronger present bias), the equity premium tends to be larger, as expected from the theoretical prediction. 


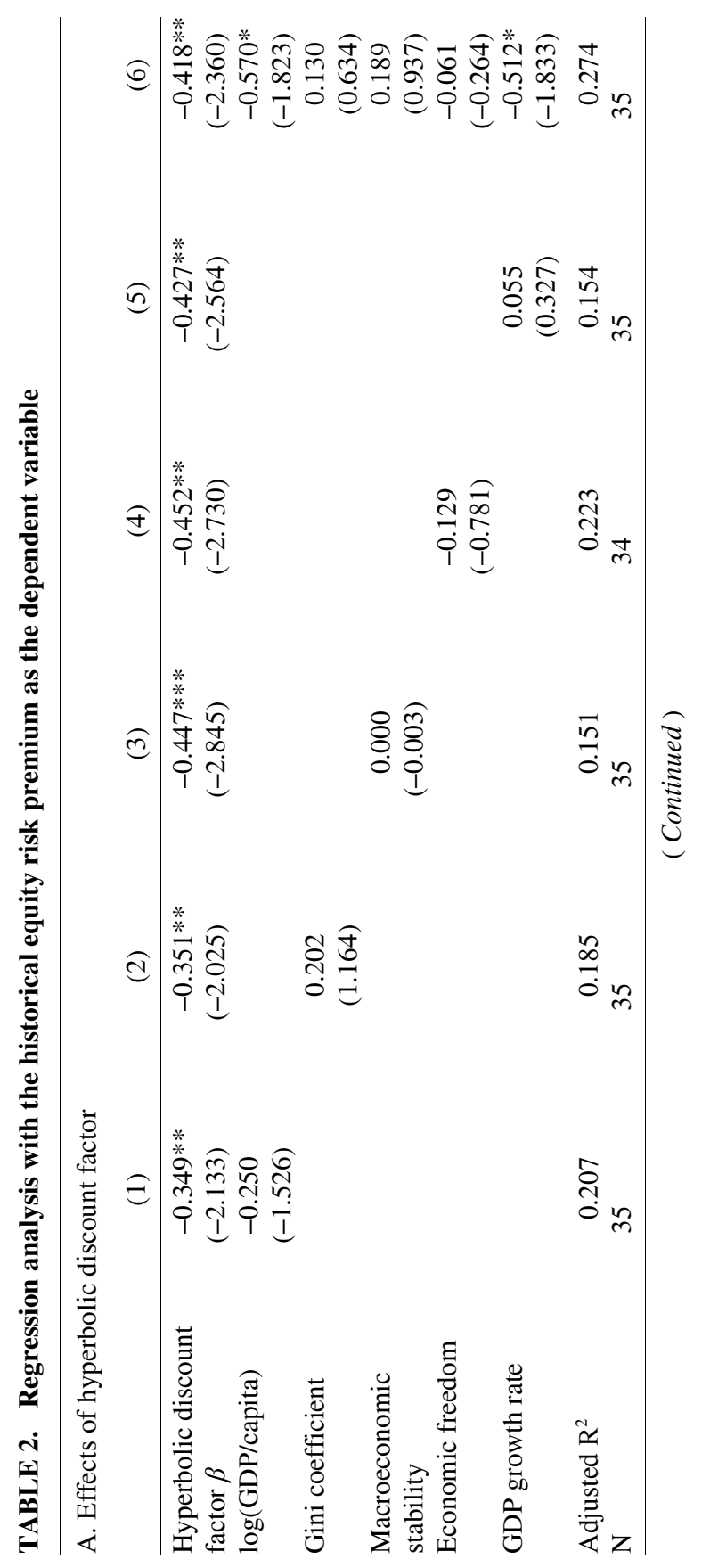




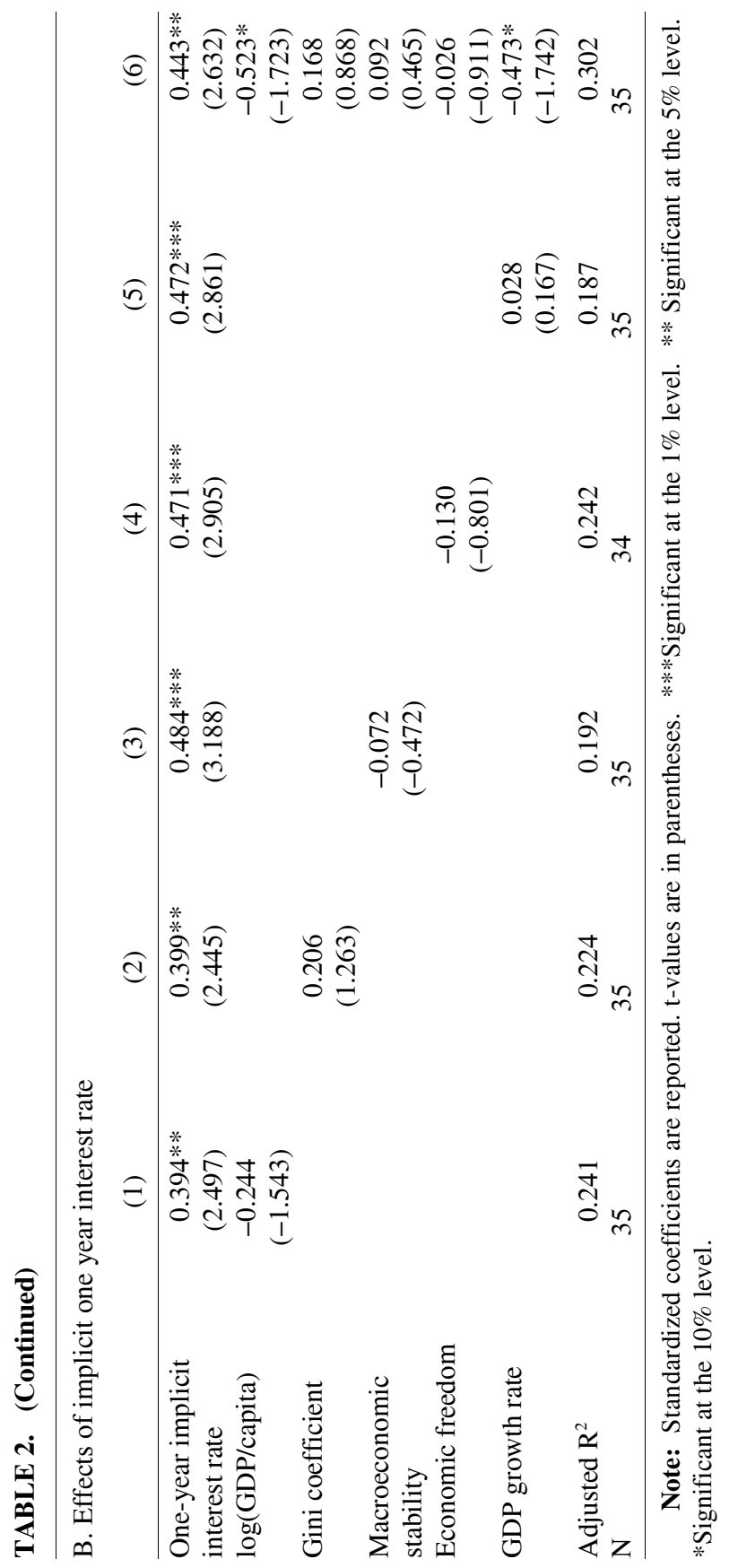


To test whether this result is merely an artifact of other underlying economic factors, we conduct a regression analysis with a number of control variables. In particular, we control for GDP per capita, macroeconomic stability, ${ }^{3}$ economic freedom ${ }^{4}$ and the GDP growth rate. Panel A of table 2 shows that the present time bias is significant at least on the $5 \%$ level.

Suppose that people who tend to discount the future more steeply are also more inclined to focus on a shorter time horizon, which corresponds to a higher equity risk premium. In this case, the equity premium should also be related to time discounting in general. To test this prediction, we replace the hyperbolic discount factor with the one-year implicit interest rate derived from the survey responses in Panel B of table 2. In all cases, the one-year implicit interest rate is significant at least at the $5 \%$ level. This shows that the equity premium is also correlated to the regular discount factor, not only to the specific hyperbolic discount factor.

Given that the historic equity premium is measured on relatively large time scales whereas the present bias is measured based on very recent survey evidence, one might wonder whether this may lead to a bias in our estimates. This bias, however, would go in the opposite direction and would rather obfuscate the relation between time discounting and the equity premium if the present time bias were to fluctuate over time. There is also some evidence in favor of the theory that time discounting in a country is rather stable over time: Recent empirical evidence from a large field survey shows that aggregate distributions of time discounting do not change much over time (Meier \& Sprenger 2010). Moreover, a connection can indeed be found between time discounting and cultural dimensions (Wang, Rieger \& Hens 2011) and cultural differences between countries are usually considered to be very stable over time (Hofstede 1991, Hofstede 2001).

Another concern is that the people who are more prone to intuitive thinking might discount the future more and might be also more likely to be prospect theory maximizers and demand higher equity premiums.

3. The World Economic Forum publishes a macroeconomic stability metric in its annual Global Competitiveness Report. The index scores 133 economies from 0 to 7 , with 7 being the best possible score. The macroeconomic stability index includes metrics on government surplus/deficit, national savings rate, inflation, interest rate spread and government debt.

4. The Index of Economic Freedom is a series of 10 economic measurements created by The Heritage Foundation and The Wall Street Journal. Its stated objective is to measure the degree of economic freedom in the world's nations. 
TABLE 3. The predictive power of System II (effortful) thinking

\begin{tabular}{llc}
\hline & Model 1 & Model 2 \\
\hline Hyperbolic discount factor $\beta$ & $-0.347 * *$ & \\
& $(-2.130)$ & $0.399 * *$ \\
Implicit interest rate & & $(2.584)$ \\
Consistency & -0.270 & $-0.279 *$ \\
& $(-1.660)$ & $(-1.810)$ \\
Adjusted $\mathrm{R}^{2}$ & 0.213 & 0.257 \\
$\mathrm{~N}$ & 35 & 35
\end{tabular}

Note: 1. Standardized coefficients are reported. $t$-values are in parentheses. 2. ***Significant at the $1 \%$ level. ** Significant at the $5 \%$ level. *Significant at the $10 \%$ level. 3. Consistency is a variable that indicates the percentage of participants who violate internality axioms less than two times while answering the eight lottery questions. Internality axioms state that the Certainty Equivalent of a lottery should be between the minimal and maximal outcomes of the lottery.

Therefore, the observed relationship between time discounting and equity risk premiums may be merely driven by the extent to which people use System I (intuition) as opposed to System II (effortful thinking). ${ }^{5}$ To test this potential cause, we proxy for effortful thinking through the responses to lottery questions in our study. In the survey, the participants were asked to state their willingness to pay for eight lotteries. We check how often the participants satisfy the internality axiom, which is that the stated willingness to pay should be between the minimal and maximal outcomes of the lottery (Gneezy, List \& Wu 2006). For each participant, we compose a dummy variable that equals 1 when there are less than two violations of internality out of the eight lotteries and 0 otherwise. We then derive a country-level consistency variable that indicates the percentage of participants who violate internality less than two times when answering questions for the eight lotteries. This consistency variable can be regarded as a proxy for effortful thinking (System II) at the country level. Table 3 shows that this factor is not significant at the $5 \%$ level with regard to predicting equity risk premiums and that it does not eliminate the significance of the time discounting predictors.

5. We thank an anonymous referee for suggesting this alternative explanation. 


\section{Conclusions}

Based on the myopic loss aversion model of Benartzi \& Thaler (1995) and Barberis \& Huang (2008), we have conjectured that differences in time discounting (particularly the present time bias) among different countries will lead to different equity premiums. This conjecture has been empirically tested using an international survey on time preferences and data on equity risk premiums across countries based on a literature survey covering a large number of studies.

Our results suggest that differences in time discounting can indeed explain some of the differences in equity premiums. Admittedly, the causality can go into both directions; namely, a high equity premium can also lead to more time discounting because of the higher expected return. However, we find that the subjective discount rates measured in our survey are far higher than the equity premiums, suggesting that equity premiums may not be the main drivers of time discounting.

Although we do not want to claim that differences in time discounting are the sole explanation for differences in equity premiums or that the equity premium puzzle can be solely explained by the myopic loss aversion approach, we think that these results offer some promising empirical evidence suggesting that this model can at least partially explain the equity premium puzzle. Moreover, we hope that our approach to comparing data on behavioral preferences across countries that exhibit behavioral differences in financial markets can also be useful in providing empirical evidence about other market behavioral finance phenomena that are otherwise difficult to analyze.

Accepted by: Prof. H. Shefrin, Guest Editor, April 2013

Prof. P. Theodossiou, Editor-in-Chief, April 2013

\section{Acknowledgements}

Support by the National Center of Competence in Research's "Financial Valuation and Risk Management" (NCCR FINRISK), Project 3, "Evolution and Foundations of Financial Markets" and the University of Zürich's "Finance and Financial Markets" University Priority Program is gratefully acknowledged. 


\section{References}

Abel, A. B. 1990. Asset prices under habit formation and catching up with the joneses. A.E.R. Papers and proceedings 80, 38-42.

Alpalhao, R., and Alves, P. 2005. The portuguese equity risk premium: what we know and what we don't know. Applied Financial Economics 15, 489-498.

Athanassakos, G. 1998. Estimating the cost of equity and equity risk-premia of Canadian firms. Multinational Finance Journal 1(3), 229-254.

Bansal, R., and Coleman, W. J. 1996. A monetary explanation of the equity premium, term premium, and risk-free rate puzzles. The Journal of Political Economy 104, 1135-1171.

Barberis, N., and Huang, M. 2008. The loss aversion/narrow framing approach to the stock market pricing and participation puzzles, in R. Mehra, ed., Handbook of the Equity Risk Premium, Elsevier, Amsterdam.

Barillas, F.; Hansen, L. P.; and Sargent, T. J. 2009. Doubts or variability?. Journal of Economic Theory 144, 2388-2418.

Barro, R. J. 2006. Rare events and the equity premium. Quarterly Journal of Economics 121(3), 823-866.

Benartzi, S., and Thaler, R. H. 1995. Myopic loss aversion and the equity premium puzzle. Quarterly Journal of Economics 110, 73-92.

Campbell, J. Y. 1999. By force of habit: A consumption based explanation of aggregate stock market behavior. Journal of Political Economy 107, 205-251.

Campbell, J. Y. 2003. Consumption based asset pricing, in von George. M. Constantinides, M. Harris \& R. M. Stulz, eds, Handbook of the Economics of Finance, North Holland, Amsterdam, Amsterdam, Netherlands, chapter 13 , pp. 803-887.

Canova, F., and Nicolo, G. D. 2003. The properties of the equity premium and the risk-free rate: An investigation across time and countries. IMF Staff Papers 50(2), 222-249.

Chen, Z., and Epstein, L. 2002. Ambiguity, risk, and asset returns in continuous time. Econometrica 70(4), 1403-1443.

Constantinides, G. M. 1990. Habit formation: A resolution of the equity premium puzzle. Journal of Political Economy 98, 519-543.

Constantinides, G. M.; Donaldson, J. B.; and Mehra, R. 2002. Junior can't borrow: A new perspective on the equity premium puzzle. Quarterly Journal of Economics 118, 269-296.

Constantinides, G. M., and Duffie, D. 1996. Asset pricing with heterogeneous consumers. Journal of Political Economy 104, 219-240.

Dimson, E.; Marsh, P.; and Staunton, M. 2006. The worldwide equity premium: A smaller puzzle, Technical report, London Business School.

Epstein, L. G., and Zin, S. E. 1991. Substitution, risk aversion, and the temporal behavior of consumption and asset returns: A empirical analysis. Journal of Political Economy 99, 263-286. 
Gneezy, U.; Kapteyn, A.; and Potters, J. 2003. Evaluation periods and asset prices in a market experiment. Journal of Finance 58(2), 821-837.

Gneezy, U.; List, J. A.; and Wu, G. 2006. The uncertainty effect: When a risky prospect is valued less than its worst possible outcome. The Quarterly Journal of Economics 121, 1283-1309.

Gneezy, U., and Potters, J. 1997. An experiment of risk taking and evaluation periods. Quarterly Journal of Economics 112(2), 631-645.

Goetzmann, W. N., and Ibbotson, R. G. 2006. History and the equity risk premium, in R. Mehra, ed., Handbook of Investments: Equity Risk Premium, Elsevier B.V.

Gollier, C. 2011. Portfolio choices and asset prices: The comparative statics of ambiguity aversion. The Review of Economic Studies 78(4), 1329-1344.

Hofstede, G. 1991. The confucius connection: From cultural roots to economic growth. Organization Dynamics 16(4), 4-18.

Hofstede, G. 2001. Culture's Consequences, Comparing Values, Behaviors, Institutions, and Organizations Across Nations, Sage Publications, Thousand Oaks CA.

Holmström, B. 1998. Private and public supply of liquidity. Journal of Political Economy 106(1).

Krebs, T. 2000. Consumption-based asset pricing with incomplete markets, working paper, Brown University.

Kyriacou, K.; Madsen, J.; and Mase, B. 2004. The equity premium. Discussion paper 04-10.

Lally, M., and Marsden, A. 2004. Estimating the market risk premium in new zealand through the siegel methodology. Accounting Research Journal 17(2), 93-101.

Madsen, J. B. 2004. The equity premium puzzle and the ex post bias, Technical report, Institute of Economics University of Copenhagen.

McGrattan, E. R., and Prescott, E. C. 2003. Average debt and equity returns: Puzzling?. American Economic Review 93, 392-397.

McGrattan, E. R., and Prescott, E. C. 2005. Taxes, regulations, and the value of u.s. and u.k. corporations. Review of Economic Studies 92, 767-796.

Mehra, R. 2003. The equity premium: Why is it a puzzle?. Financial Analysts Journal 59(1), 54-69.

Mehra, R. 2007. The equity premium in india, in K. Basu, ed., Oxford Companion to Economics in India, Oxford University Press.

Mehra, R. 2008. The equity premium puzzle: A review. Foundations and Trends in Finance 2, 1-81.

Mehra, R., and Prescott, E. C. 1985. The equity premium puzzle. Journal of Monetary Economics XV, 145-161.

Mehra, R., and Prescott, E. C. 1988. The equity premium: A solution? Journal of Monetary Economics 22, 133-136.

Mehra, R., and Prescott, E. C. 2003. The equity premium puzzle in retrospect, in von George. M. Constantinides, M. Harris \& R. M. Stulz, eds, Handbook 
of the Economics of Finance, North Holland, Amsterdam, Netherlands, pp. 888-936.

Meier, S., and Sprenger, C. 2010. Stability of time preferences, IZA Discussion Papers 4756, Institute for the Study of Labor (IZA).

Rieger, M. O., and Wang, M. 2012. Can ambiguity aversion solve the equity premium puzzle? Survey evidence from international data. Finance Research Letters 9, 63-72.

Rietz, T. A. 1988. The equity risk premium: A solution. Journal of Monetary Economics 22, 117-131.

Salomons, R., and Grootveld, H. 2003. The equity premium: emerging vs. developed markets. Emerging Markets Review 4(2), 121-144.

San Martin, J. R. F., and Lillo, S. Z. 2003. The equity risk premium in emerging markets: The case of Chile. working paper.

Schackman, J. D. 2006. The equity premium and market integration: Evidence from international data. Journal of International Financial Markets, Institutions and Money 16(2), 155-179.

Thaler, R.; Tversky, A.; Kahneman, D.; and Schwartz, A. 1997. The effect of myopia and loss aversion on risk taking: An expeirmental test. The Quarterly Journal of Economics 112(2), 647-661.

Wang, M.; Rieger, M. O.; and Hens, T. 2011. How time preferences differ: Evidence from 45 countries, SSRN working paper.

Zeisberger, S.; Langer, T.; and Trede, M. 2007. A note on myopic loss aversion and the equity premium puzzle. Finance Research Letters 4, 127-136. 